\title{
Unusual Arboreality in a Common Sand Boa, Eryx conicus (Schneider 1801) (Reptilia: Squamata: Erycidae)
}

\author{
Subhadeep Chowdhury ${ }^{1}$, Saurav Dwari ${ }^{2}$, and Anirban Chaudhuri ${ }^{3}$
}

${ }^{1}$ Krishnachak, Dhurkhali, Howrah, West Bengal 711410, India (isuvodeep@gmail.com)

${ }^{2}$ Gourangachak, Howrah, West Bengal 711410, India (saurav.dwari@gmail.com)

${ }^{3}$ Nature Mates Nature Club, 6/7, Bijoygarh, Kolkata-700032, West Bengal, India (abchaudhuri@gmail.com)

Common Sand Boas, Eryx conicus (Schneider 1801), are stout-bodied, medium-sized snakes with strongly keeled scales (Das 2002). The species is abundant in arid localities (Das 2002) and is found throughout the Indian Sub-continent, including Pakistan, Nepal, Sri Lanka, and Bangladesh, but excluding the Andaman and Nicobar Islands (Whitaker and Captain 2008). Although mostly crespuscular or nocturnal (Das 2002), these snakes are known to hunt by day (Whitaker and Captain 2008). They are strong burrow- ers in loose sand or silty soil (Sharma 2007) and generally constrict prey, which includes small mammals, birds, reptiles, amphibians, and even large insects (Smith 1943; Das 2002; Sharma 2007; Whitaker and Captain 2008). Typical foraging behavior is for an individual to hide itself in the substrate or surface litter and ambush any prey that comes within striking range (Whitaker and Captain 2008).

Herein we report unusual arboreality in an E. conicus from Rameshwar Mahadev Mandir, Jhargram District, West

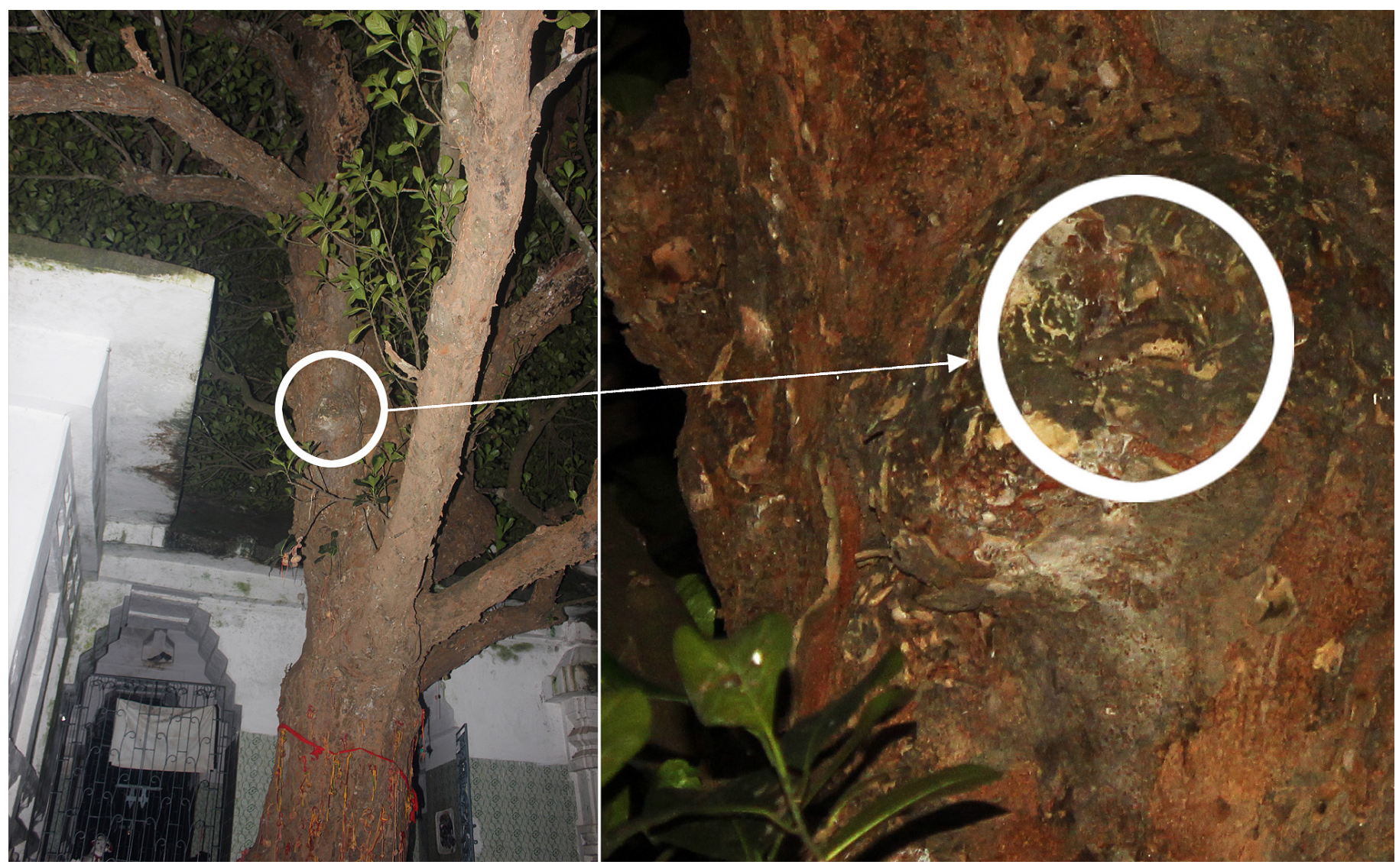

Fig. 1. A Common Sand Boa (Eryx conicus) in a hole in a Jackfruit Tree (Artocarpus heterophyllus) approximately $5 \mathrm{~m}$ above the ground. Photograph by Subhadeep Chowdhury. 
Bengal, India $\left(22.146574^{\circ} \mathrm{N}, 87.054212^{\circ} \mathrm{E}\right.$; elev. $47 \mathrm{~m}$ asl). At $0137 \mathrm{~h}$ on 13 October 2017, SC and SD observed an E. conicus extending part of its body out of a hole in a Jackfruit Tree (Artocarpus heterophyllus) approximately $5 \mathrm{~m}$ above the ground (Fig. 1). These terrestrial burrowing snake are not known to climb high into trees. We suggest that the snake was waiting to ambush some kind of arboreal prey that could include rodents, bats (which were observed on the tree), or geckos. Local residents told us that they sometimes saw more than one snake of the same kind even higher on that tree than the individual we encountered. Only additional field research can determine if this behavior is truly unusual or has merely been overlooked.

\section{Acknowledgements}

We thank Sunipam Mahakul and Nirmal Nayek for help during fieldwork.

\section{Literature Cited}

Das, I. 2002. A Photographic Guide to Snakes and Other Reptiles of India. New Holland Publishers Ltd., London, UK.

Sharma, R.C. 2007. The Fauna of India and the Adjacent Countries. Reptilia. Volume-III (Serpentes). Zoological Survey of India, Kolkata.

Smith, M.A. 1943. The Fauna of British India, Ceylon and Burma, Including the Whole of the Indo-Chinese Sub-region. Reptilia and Amphibia. Volume IIISerpentes. Taylor and Francis, London.

Whitaker, R. and A. Captain, A. 2008. Snakes of India: The Field Guide. Draco Books, Chennai, India. 